\title{
Mini Review \\ Physical exercise in type 1 diabetes: recommendations and care
}

\author{
Luis Paulo Gomes Mascarenhas \\ Universidade Estadual do Centro Oeste, Irati, PR, Brasil \\ Juliana Pereira Decimo \\ Valderi Abreu de Lima \\ Gabriela de Carvalho Kraemer \\ Kátia Regina Castro de Lacerda \\ Suzana Nesi-França \\ Universidade Federal do Paraná, Curitiba, PR, Brasil
}

\begin{abstract}
The management of type 1 diabetes mellitus (T1DM) is based on three pillars: insulin therapy, nutrition, and regular practice of physical activity. Physical exercises are associated with metabolic demands that depend on the individual's energy stores and level of physical conditioning, and vary according to environmental conditions and intensity, duration, and type of exercise. All these factors, added to eventual distress with competitions, exert influence on glucose metabolism. The athletic career of diabetic individuals is often hindered by a risk of hypoglycemia during and after the exercise, frequent hyperglycemia before, during, and after certain physical activities, occurrence of ketoacidosis, and presence of chronic microvascular and macrovascular complications. Aerobic exercises reduce the levels of blood glucose while anaerobic exercise may promote transient hyperglycemia. Although diabetic individuals may achieve excellence in sport, their physical performance should be maximized by strict blood glucose control, adequate modifications in insulin dose on the day of the exercise, and appropriate nutritional intake. This review discusses the impact of physical exercise on glucose metabolism, as well as nutritional considerations and strategies appropriate to the practice of physical exercises by patients with T1DM.
\end{abstract}

Keywords: diabetes mellitus, type 1, exercise, physical activity, blood glucose, nutrition therapy

\section{Introduction}

Treatment of type 1 diabetes mellitus (T1DM) is comprised of medications, proper nutrition, and regular physical activity ${ }^{1}$. Due to its therapeutic benefits, physical exercise is widely recommended for diabetic patients. Many diabetics turn the regular practice of physical activity into a routine of training that ranges from participation in recreational activities, games, or school competitions, to even Olympic careers. Athletic activities are considered safe for patients with T1DM, provided that the athletes and the multidisciplinary team caring for them pay attention during the exercise to the particularities and requirements of the disease ${ }^{2}$.

However, during training and competition, athletes with T1DM face some challenges and are required to deal with physiological demands associated with exercising at different intensities, such as special nutritional requirements, changes in meal schedule, and physical distress associated with competition ${ }^{3}$.

In addition to these factors, athletes with T1DM face a substantial risk of hypoglycemia during and after exercising. There are also frequent reports of hyperglycemia before, during, and after some types of exercises, which add to the risk of ketoacidosis, and chronic microvascular and macrovascular complications may hinder the career of athletes with T1DM ${ }^{4,5,6}$.

Despite the limited number of well-controlled studies supporting effective treatment plans for diabetic patients performing regular physical training, this review aims to discuss the current evidence regarding the impact of physical exercise on the dynamics of blood glucose control, in addition to nutritional considerations and appropriate strategies for the practice of physical exercise by patients with T1DM.

\section{Blood glucose regulation and exercise in patients with T1DM}

A routine of regular physical exercises may bring several health benefits to diabetic patients, including a decrease in cardiovascular risk, maintenance of body weight, reduction in blood pressure, and improvements in blood glucose control and well-being $6,7,8$.

Guidelines of the American Diabetes Association ${ }^{2}$ and the American College of Sports Medicine ${ }^{9}$ recommend that diabetic individuals are prescribed individualized exercise regimens with well-defined objectives. These recommendations include participation in exercise sessions of moderate intensity for at least 150 minutes a week in the absence of contraindications such as diabetic neuropathy, proliferative diabetic retinopathy, uncontrolled hypertension, and metabolic ketoacidosis ${ }^{10}$.

The practice of physical exercise is associated with metabolic demands that depend on the exercise type (aerobic or anaerobic, according to the predominant metabolic energy source 
required during exercise), form (continuous or intermittent, according to the interruption of the sets of exercise), intensity (very light, light, moderate, vigorous, near-maximal to maximal)

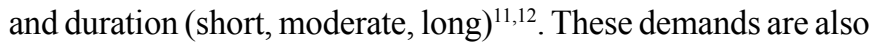
determined by ambient conditions (cold, heat, humidity, time of the day, altitude), and the individual's energy stores and level of physical fitness ${ }^{13,14}$. The degree of effort exerted during physical activity may be indirectly measured by the level of oxygen consumption. The maximum amount of oxygen $\left(\mathrm{VO}_{2 \mathrm{~m}}\right.$ ax $)$ utilized by the body at each minute during the exercise measures the maximum aerobic effort capacity. During exercises of moderate intensity (40-59\% of the $\mathrm{VO}_{2 \mathrm{~m}}$ ax or $55-69 \%$ of the maximum heart rate), the aerobic metabolism generally predominates, and carbohydrates and free fatty acids are used as energetic substrates ${ }^{15}$. When the oxygen requirement increases above $75 \%$ of the $\mathrm{VO}_{2 \mathrm{~m}}$ ax, the exercise acquires anaerobic characteristics. However, low effort levels may be anaerobic at high altitudes and when performed by individuals who are sedentary, anemic, or with cardiac and pulmonary disease ${ }^{16}$.

The transition from rest to moderate exercise is characterized by activation of sympathetic and hormonal systems that stimulate the use of the glucose stored in the muscle and liver, and the release of free fatty acids by the adipose tissue ${ }^{17}$. In nondiabetic individuals, a reduction of $8 \mathrm{mg} / \mathrm{dL}$ in blood glucose levels and/or blood glucose concentrations around $65-70 \mathrm{mg} /$ $\mathrm{dL}$ leads to increases in glucagon and epinephrine levels ${ }^{18,19}$. Alpha-adrenergic stimulation of pancreatic islets inhibits insulin secretion and releases glucagon, leading to neoglucogenesis and glycogenolysis and increasing glucose production by about 5 $\mathrm{mg} / \mathrm{kg} / \mathrm{min}^{19}$. This process is a key factor in maintaining stable blood glucose levels $(80-100 \mathrm{mg} / \mathrm{dL})$ during exercise and preventing hypoglycemia, as the consumption of glucose by the muscle may be around $3 \mathrm{mg} / \mathrm{kg} / \mathrm{min}$ during moderate exercise ${ }^{20}$.

Rates of glucose oxidation during moderate intensity exercise are estimated at $2 \mathrm{mg} / \mathrm{kg} / \mathrm{min}$ in adults with T1DM (21) and $1.5 \mathrm{mg} / \mathrm{kg} / \mathrm{min}$ in adolescents with $\mathrm{T}_{1} \mathrm{DM}^{22}$. These rates lead to a fast decrease in serum glucose concentration due to an impairment in the glucagon counter-regulatory response. In some patients with T1DM, glucagon response to reduced blood glucose levels ${ }^{23}$ may be impaired after a few years, although there have been reports of an appropriate release of glucagon during exercise in these patients ${ }^{24}$. In any case, even with a satisfactory glucagon and epinephrine response to physical exercise in T1DM, elevated levels of exogenous insulin may directly or indirectly inhibit glucagon secretion due to its antagonist effect, and reduce lipolysis and proteolysis ${ }^{25-27}$.

Chokkalingam, Tsintzask, Norton, Jewell, Macdonald, Mansel $1{ }^{28}$ have observed that during moderate intensity exercise, fat oxidation accounts for $15 \%$ of the total energy expenditure in T1DM patients using high insulin doses and $23 \%$ in those using low insulin doses. These values are significantly lower than those in nondiabetic individuals, in whom fat oxidation accounts for about $40 \%$ of the total energy expenditure under similar conditions ${ }^{29}$.

It is worth mentioning that in patients with T1DM, hyperglycemia itself inhibits lipid oxidation during exercise ${ }^{30}$, and that in those with glucose levels $\sim 97 \mathrm{mg} / \mathrm{dL}$ and insulin levels $\sim 122 \mathrm{mmol} / \mathrm{L}$ during exercise, rates of lipid oxidation are similar to those in nondiabetics ${ }^{28}$. Following this line of thought, the high rate of carbohydrate oxidation during physical exercise in T1DM could be one of the factors leading to a decrease in blood glucose levels.

Several factors affect the levels of plasma glucose in diabetic athletes, and hypoglycemia may manifest immediately after the exercise or hours later. During or soon after moderate intensity exercises, it is possible that an energy balance inadequate to the demand of the exercise, added to an excessive amount of insulin administered to the subcutaneous in areas involved in the exercise, increases the rates of insulin absorption promoting hypoglycemia ${ }^{31,32}$. Physical exercise can also amplify the effects of insulin because it facilitates the transport of glucose through the cell membrane and increases muscle glucose absorption by up to 20 times. In fact, a single exercise session may increase the insulin sensitivity by up to $40 \%$ for 48 hours $^{33}$. These effects promoted by physical exercises benefit the glycemic control both in nondiabetic and diabetic individuals, but in the latter they may lead to late hypoglycemia.

Studies report that the two main defenses against hypoglycemia are impaired in T1DM patients as these individuals are unable to decrease the levels of circulating insulin and have impaired glucagon response $e^{23,25,26}$. Thus, only epinephrine remains a front line counter-regulatory defense against hypoglycemia in T1DM patients. Even then, the epinephrine response may be less robust and occur only at low blood glucose levels ${ }^{34,35}$. Due to that, signs and symptoms of hypoglycemia related to autonomic regulation are impaired in these individuals $\mathrm{s}^{36,37}$.

Signs and symptoms of hypoglycemia due to adrenergic (sympathomimetic) stimulation include hunger, tremor, anxiety, tachycardia, and palpitation, whereas those due to neuroglycopenia (reduced availability of glucose to support cerebral functions) include weakness, fatigue, loss of coordination, disjointed speech, and blurred vision ${ }^{38}$. It has been postulated that repeated episodes of hypoglycemia reduce the sensitivity to epinephrine, a phenomenon known as hypoglycemia-associated autonomic failure (HAAF) ${ }^{39}$. Davis, Shavers, Mosqueda-Garcia, $\mathrm{Costa}^{40}$ have reported that only two episodes of hypoglycemia at glucose levels below $70 \mathrm{mg} / \mathrm{dL}$ are sufficient to reduce $30 \%$ of the counter-regulatory response in the following episode of hypoglycemia.

Sandoval, Aftab-Guy, Richardson, Ertl, Davis ${ }^{35}$ evaluated T1DM patients exercising at mild to moderate intensity $(30 \%$ and $50 \%$ of the $\mathrm{VO}_{2 \mathrm{~m}}$ ax, respectively) and presenting post-exercise hypoglycemia. The authors observed that these episodes of hypoglycemia reduced the response of the counter-regulatory hormones to a new episode of hypoglycemia in the following exercise session. Galassetti, Tate, Neill, Morrey, Wasserman, Davis $^{41}$ have reported that exercise sessions lasting more than 30 minutes and associated with hypoglycemia may induce HAAF in progressively lower levels of blood glucose $(70,60$, and 50 $\mathrm{mg} / \mathrm{dL}$ ) at each new exercise session.

Hypoglycemia associated with physical exercise can occur hours after the exercise and may occasionally occur in the evening. Additionally, it has been speculated that an increased cortisol release during prolonged physical exercise may contribute 
to the development of $\mathrm{HAAF}^{42}$, although a reduction in cortisol production has not been shown to improve HAAF after exercise. In contrast, the absence of hypoglycemia for a few weeks may improve the response to epinephrine by increasing the glycemic threshold for the release of counter-regulatory hormones and exacerbate the signs of hypoglycemia ${ }^{37}$.

It is important to emphasize that sexual dimorphism seems to substantially influence the response of the counter-regulatory hormones to blood glucose levels. During prolonged exercise, women with T1DM present lower levels of epinephrine, norepinephrine, and growth hormone compared with men. Despite the low response to catecholamines, lipolytic rates have been described as significantly higher in women than men, suggesting that women have a greater beta-adrenergic sensitivity ${ }^{43}$.

Galassetti, Tate, Neill, Morrey, Davis ${ }^{43}$ have observed that males, when compared with females, present an attenuated decrease in glucagon, fat oxidation, and endogenous glucose production after physical exercise at $50 \%$ of the $\mathrm{VO}_{2 \mathrm{~m}}$ ax. There is also an apparent sexual dimorphism in glucagon/insulin rate in favor of women, resulting in a better endogenous glucose production. In a way, the fact that women preserve fat oxidation after exercise-induced hypoglycemia confers a protective benefit, and therefore, lower susceptibility to HAAF.

Hypoglycemia is a common and dreaded complication in athletes with $\mathrm{T}^{\mathrm{DDM}}{ }^{42,44}$. Levels of blood glucose in athletes or individuals with T1DM who perform routine training should be maintained between 120 and $180 \mathrm{mg} / \mathrm{dL}$, although patients often become aware of their ideal levels of blood glucose for each particular exercise.

The best approach to hypoglycemia associated with exercise is to prevent its occurrence. Athletes with T1DM, and those professionals and friends close to them, must be alert to signs and symptoms of hypoglycemia, which should be treated with ingestion of carbohydrates, preferably with glucose. If the patient is unconscious and unable to ingest food or fluids orally, they must receive a glucagon injection ${ }^{45}$.

Generally, youths with T1DM seem to have a 20\% lower aerobic capacity than healthy youths. However, physically active individuals with well-controlled T1DM often have an aerobic capacity within the normal age range $e^{46,47}$. Several cardiovascular, metabolic, and muscular impairments in patients with T1DM help explain the decrease in aerobic and anaerobic performances ${ }^{23,36,46,48}$. In a recent study, Rissanen, Tikkanen, Koponen, Aho, Peltonen ${ }^{49}$ observed that physically active adults with T1DM present a lower cardiovascular response to exercise at peak working rate, in addition to a lower systolic volume, systemic vascular resistance, $\mathrm{VO}_{2 \mathrm{~m}} \mathrm{ax}$, and blood flow. These observations reflect central and peripheral limitations in diabetic individuals when compared with nondiabetic ones. In contrast, studies have not found significant differences in aerobic capacity in diabetic adults who are long distance runners or very active when compared with nondiabetics ${ }^{50,51}$. Therefore, it is still uncertain whether the reduced aerobic capacity in T1DM is due to poor muscular oxygenation or to the amount of muscle capillaries ${ }^{52}$.

Anaerobic exercises, such as sprints, short-distance races, or even collective sports, generally do not cause significant changes in blood glucose, but when this occurs it is often associated with an increase in blood glucose levels in individuals with T1DM due to an increase in catecholamines and production of lactate ${ }^{53,54}$. The increase in levels of lactate and catecholamines during anaerobic exercise is known to reduce the consumption of glucose and free fatty acids by the muscle ${ }^{55}$ and increase the hepatic production of glucose via blood lactate ${ }^{56}$.

Exercise-induced hyperglycemia may last for hours after the end of an activity and somehow interfere with the glycemic control and later performance in sport ${ }^{44}$. Studies suggest that high-intensity intermittent exercises attenuate the decrease in blood glucose levels that are frequently observed in moderate intensity exercises ${ }^{4,57-59}$.

Harmer et al..$^{60}$ have reported that high-intensity exercises lasting 30 seconds result in an increase in blood glucose levels during and after the exercise in patients with T1DM. Such an increase may be related to plasma levels of lactate, as lactate may induce insulin resistance during high-intensity exercise ${ }^{27,61}$. This phenomenon explains the increase in blood glucose levels even in the presence of increased insulin levels.

The changes in blood glucose levels observed after highintensity anaerobic training suggest that this type of training is associated with better insulin clearance, reduced catecholamine stimulation, and increased cellular content of glucose transporter type 4 (GLUT4) ${ }^{60}$. The transport of blood glucose to the myocyte is mainly performed by GLUT4. In response to insulin (postexercise) or muscle contraction and stimulated by the increase in calcium concentration during exercise, GLUT4 translocates both to the cellular membrane and to the T-tubules ${ }^{62}$.

Interestingly, studies indicate that only 10 seconds of highintensity aerobic exercise are required to prevent post-exercise hypoglycemia in patients with $\mathrm{T}^{\mathrm{DDM}} \mathrm{M}^{57,63}$. Similarly, the practice of exercising with weights before aerobic exercises attenuates the decrease in blood glucose $\mathrm{e}^{64}$.

Another study attempted to mimic sports games using highintensity stimuli with 4 -second shots followed by 2 minutes of active recovery for 20 minutes. The authors observed that the association of anaerobic and aerobic exercises did not increase the risk of hypoglycemia ${ }^{4}$. Thus, the increase in catecholamines and growth hormone levels during high-intensity exercise may prevent hypoglycemia, as after exercise these hormones increase the hepatic production of glucose and inhibit the uptake of glucose in response to insulin stimulation ${ }^{56,65}$.

Although most studies related to the prescribing of anaerobic exercises to T1DM patients have shown positive results regarding the reduction of cases of hypoglycemia associated with acute exercise, the risk may increase hours later ${ }^{66}$. Still, more studies are required to provide a scientific basis for the development of guidelines in this setting.

\section{Nutritional recommendations: schedules, type of nutrients, and hydration}

Carbohydrates must comprise $50-60 \%$ of the daily diet of diabetic athletes performing regular exercises ${ }^{67}$, which should 
be coordinated with the time of the exercise and the dose of insulin. This approach is fundamental to an ideal glycemic control, maintenance of muscle mass, and storage of hepatic and muscular glycogen, optimizing the exercise performance, reducing fatigue, and preventing complications ${ }^{3}$.

Before performing exercises, T1DM patients should follow a diet based on the following recommendations:

A) Ingestion of $200-350 \mathrm{~g}(4 \mathrm{~g} / \mathrm{kg})$ of carbohydrates, 3-6 hours before the exercise. This recommendation has proven effective in improving physical performance ${ }^{68}$. Although patients with T1DM should ingest $60-90 \mathrm{~g}$ of carbohydrates per meal, diabetic patients undergoing training are required to increase their glycogen stores before competitions and athletic activities by increasing the amount of carbohydrates in their meals, monitoring the blood glucose levels, and if necessary, adjusting the dose of insulin accordingly ${ }^{69}$.

B) Ingestion of an additional amount of $1 \mathrm{~g}$ of carbohydrate per $\mathrm{kg}$ of weight is recommended 1 hour before the exercise. Preference should be given to low-fat food or fluids ${ }^{12}$.

C) If the exercise lasts for less than 45 minutes, a snack with $15 \mathrm{~g}$ of carbohydrates ingested $15-30$ minutes before the activity has been reported to be sufficient ${ }^{70}$.

During physical exercises lasting more than 45 minutes, or even after their end, strategies may be used to maintain carbohydrate oxidation and prevent a reduction in glycogen stores (Table 1).

Table 1. Nutritional recommendations for T1DM patients involved in physical activities.

\begin{tabular}{c} 
During the activity \\
\hline $\begin{array}{c}\text { Ingestion of } 0.5-0.6 \mathrm{~g} \text { of carbohydrates per kg of body weight for } \\
\text { every hour of activity. }\end{array}$ \\
In activities lasting more than $2 \mathrm{hours}$, ingestion of a larger amount \\
of carbohydrates $(0.8 \mathrm{~g} / \mathrm{kg})$ may be necessary. \\
During prolonged and high-intensity $\left(>70 \% \mathrm{VO}_{2 \mathrm{~m}} \mathrm{ax}\right)$ train- \\
ing or competitions, ingestion of $15 \mathrm{~g}$ of carbohydrates at each \\
$30-45$-minute interval. \\
This amount of carbohydrates may increase blood glucose levels \\
by 30-50 mg/dL, 15-30 minutes after their ingestion (Gonder- \\
Frederick, 2001). \\
Food rich in solid or liquid carbohydrate may be ingested. \\
Liquid foods help with hydration, while solid foods may prevent \\
hunger. However, liquid foods are more widely recommended \\
(Coyle \& Montain, 1992).
\end{tabular}

\section{After the activity}

Ingestion of $1.5 \mathrm{~g}$ of carbohydrate per $\mathrm{kg}$ of body weight after the end of prolonged exercises ( $>90$ minutes).

Ingestion of carbohydrates immediately after the exercise helps to replenish glucose stores in the muscle and liver (Ivy, Katz \& Cutler, 1988).

An additional amount of $1.5 \mathrm{~g}$ of carbohydrate per $\mathrm{kg}$ of body weight may be required 1-2 hours after the exercise to reduce the risk of post-exercise hypoglycemia.

Blood glucose monitoring is required immediately after the exercise and 1-2 hours later to adjust the caloric intake and insulin dose.

As for hydration, the body may eliminate up to 2.5 liters of fluids daily, depending on environmental and individual conditions. During rest, an individual weighing $70 \mathrm{~kg}$ produces $60 \mathrm{~W}$ of heat, whereas they may produce up to $1 \mathrm{~kW}$ of heat during intense exercise. To counterbalance the production of heat, the body must produce $1.5-2$ liters of sweat ${ }^{71}$. Thus, to prevent the complications associated with dehydration during physical activities, individuals with T1DM must ingest fluids before, during, and after the exercise. Adequate hydration helps control the body temperature and reduce the overload to the cardiovascular system. Ingestion of water and isotonic drinks is, therefore, a very important strategy ${ }^{3}$ (Table 2 ).

Table 2. Recommendations regarding fluid ingestion before, during, and after physical activities for patients with T1DM.

\section{Recommendations for ingestion of fluids}

Drink 3-4 cups of water approximately 2 hours before the activity. Drink 1-2 cups of water between 10-15 minutes before the exercise. Drink half a glass of water at intervals of 10-20 minutes during the exercise, mainly in prolonged activities.

In prolonged activities, isotonic drinks containing at least $8 \%$ of carbohydrates (50\% dilution in natural fruit juices and/or isotonic fluids) are generally the best options to replenish fluids and calories.

After the end of the exercise, drink 1-2 cups of water for each kilogram of weight lost during the exercise.

Studies demonstrated the importance in blood glucose control and caloric ingestion even when the values are higher than $100 \mathrm{mg} / \mathrm{dL}^{27,72,47,64}$. Due to biological individualities, metabolic responses to physical training, and environmental variations in temperature, trainers, nutritionists, and physiologists must guide the diabetic patients to determine the best strategy for fluid ingestion and adjustment of carbohydrate content in the diet for adequate hydration and maintenance of normal blood glucose levels.

\section{Strategies and care for the practice of physical exercises regarding insulin}

As insulin has been used illicitly by some athletes (especially weightlifters and fighters), it has been listed as a banned substance since 2005. Any athlete with T1DM who wants to compete in national or international sports events following international antidoping regulations, is required to have an appropriate documentation provided by a physician about the diagnosis and treatment of the disease ${ }^{13}$.

In addition to determining the levels of capillary blood glucose as part of the routine in T1DM, glucose levels should also be determined 1-2 hours and, again, moments before the exercise, so that the glucose trend can be determined and appropriate procedures adopted. If the glucose levels show a trend toward a decrease (values that are lower just moments before the exercise than 2 hours before), carbohydrates may be ingested as a preventive strategy. In contrast, if the trend points toward an increase (a higher glucose level before the beginning of the exercise) this strategy may not be necessary ${ }^{73}$.

In addition to measuring the glucose levels before the exercise, they should also be monitored at the end of the exercise 
and 1-2 hours later. In this situation, if the level is too low, the patient should ingest carbohydrates to reduce the risk of hypoglycemia. In the case of anaerobic exercises in which hyperglycemia may occur due to the intensity of the exercise, insulin adjustments should be avoided or conducted in small $\operatorname{doses}^{74}$. Another aspect to be observed is the possibility that the athlete may be using anabolic agents, as these agents may induce or worsen hyperglycemia.

Regarding the type of insulin, the absorption of mealtime and basal insulin can change with exercise. In the case of NPH insulin, the absorption doubles with increased temperature at the injection site. This occurs primarily due to increased subcutaneous blood flow, which improves the absorption of free insulin, regardless of the type of insulin, although it may also increase the dissociation of complex insulin in the case of NPH insulin, or microprecipitates with insulin glargine. With insulin detemir, however, more insulin is also expected to enter the circulation with the increased absorption of free insulin detemir; however, once in circulation, insulin detemir enters into a large pool of bound albumin, so the effect on absorption changes is blunted, and insulin detemir appears to promote less hypoglycemia after exercise in individuals with relatively well-controlled T1DM ${ }^{75}$.

Another important factor regarding the insulin type is that lispro insulin has faster absorption than regular insulin; this improves the early postprandial glycemic increase, reducing the risk of late postprandial hypoglycemia ${ }^{76}$.

Exercises below $70 \%$ of the $\mathrm{VO}_{2 \mathrm{~m}}$ ax and lasting less than 30 minutes require only minimum adjustments in insulin therapy ${ }^{74}$. A $30-50 \%$ reduction in rapid-acting insulin after exercise has been reported as effective in reducing the risk of hypoglycemia. Another important step is to reduce $10-30 \%$ of the total daily insulin ${ }^{67,74}$.

Individuals with T1DM performing physical activities at moderate intensity for 45 minutes during the afternoon or early evening have a $30-40 \%$ increased risk of nocturnal hypoglycemia $^{77,78}$. This may be problematic because patients may be unaware of hypoglycemia during sleep. Therefore, a $20-50 \%$ reduction in the dose of basal insulin or a snack with complex carbohydrates and proteins is advisable in this situation ${ }^{74,76,79}$.

\section{Final considerations}

In summary, a large number of neuroendocrine disorders may influence the regulation of blood glucose during exercise. Glycemic control during the practice of physical activities then becomes challenging for professionals working with T1DM patients. Studies indicate that aerobic exercises promote reductions in blood glucose levels, whereas anaerobic exercises may promote transient hyperglycemia. Although diabetic individuals may achieve excellence in sport, rigorous blood glucose control and appropriate insulin modifications on the day of the exercise, in addition to appropriate nutritional intake, are fundamental to maximize their physical performance. The fitness improvement associated with regular physical exercise in T1DM patients clearly demonstrates the importance of physical activities in these patients' health and quality of life.

\section{References}

1. Anaruma CP, Ferreira Jr M, Sponton CHG, Delbin MA, Zanesco A. Heart rate variability and plasma biomarkers in patients with type 1diabetes mellitus: Effect of a bout of aerobic exercise. Diabetes Res Clin Pract. 2016; 111: 19-27.

2. American Diabetes Association. Position Statement: Physical Activity/Exercise and Diabetes. Diabetes Care. 2004; 27 (Suppl 1): S58-S62.

3. American Diabetes Association. Foundations of Care: Education, nutrition, physical activity, smoking cessation, psychosocial care, and immunization. Diabetes Care. 2015; 38 (Suppl 1): S20-30.

4. Arutchelvam V, Heise T, Dellweg S, Elbroendt B, Minnst I, Home PD. Plasma glucose and hypoglycaemia following exercise in people with type 1 diabetes: a comparison of three basal insulins. Diabet Med, 2009; 26 (10): 1027-1032.

5. Bolli G, De Feo P, Compagnucci P. Abnormal glucose counterregulation in insulin dependent diabetes mellitus: interaction of anti-insulin antibodies and impaired glucagon and epinephrine secretion. Diabetes. 1983; 32 (2): 134-141.

6. Brooks GA. Cell-cell and intracellular lactate shuttles. J Physiol. 2009; 587 (23): 5591-600.

7. Brugnara L, Vinaixa M, Murillo S, Samino S, Rodriguez MA, Beltran A, Lerin C, Davison G, Correig X, Novials A. Metabolomics approach for analyzing the effects of exercise in subjects with type 1 diabetes mellitus. Plos One. 2012; 7 (7): e40600.

8. Bussau VA, Ferreira LD, Jones TW, Fournier PA. The 10-s maximal sprint: a novel approach to counter an exercisemediated fall in glycemia in individuals with type 1 diabetes. Diabetes Care 2006; 29 (3): 601-6.

9. Bussau VA, Ferreira LD, Jones TW, Fournier PA. A 10-s sprint performed prior to moderate intensity exercise prevents early post-exercise fall in glycaemia in individuals with type 1 diabetes. Diabetologia. 2007; 50 (9): 1815-1818.

10. Camacho RC, Galassetti P, Davis SN. Glucoregulation during and after exercise in health and insulindependent diabetes. Exerc Sport Sci Rev. 2005;. 33 (1): 17-23.

11. Choi CS, Kim YB, Lee FN, Zabolotny JM, Kahn BB, Youn JH. Lactate induces insulin resistance in skeletal muscle by suppressing glycolysis and impairing insulin signaling. Am J Physiol Endocrinol Metab. 2002; 283: E233-E240.

12. Chokkalingam K, Tsintzask K, Norton L, Jewell K, Macdonald IA, Mansell PI. Exercise under hyperinsulinemic conditions increases whole-body glucose disposal without affecting muscle glycogen utilization in Type 1 diabetes. Diabetologia. 2007; 50 (2): 414-421.

13. Coyle E, Montain S. Benefits of fluid replacement with carbohydrate during exercise. Med Sci Sports Exerc. 1992; 24: S324-30.

14. Cranston I, Lomas J, Maran A, Macdonald I, Amiel SA. Restoration of hyoglycaemia awareness in patients with longduration insulin-dependent diabetes. Lancet. 1994; 344 (8918): 283-287.

15. Cryer PE. Iatrogenic hypoglycemia as a cause of hypoglycemiaassociated autonomic failure in IDDM. Diabetes. 1992; 41(3): $255-260$. 
16. Cryer, P.E. Exercise-related hypoglycemia-associated autonomic failure in diabetes. Diabetes. 2009; 58: 1951-1952.

17. Cryer PE. Glucose homeostasis and hypoglycemia. In: Kronenberg HM, Melmed S, Polonsky KS, et al, editors. Williams Textbook of Endocrinology. 12th edition, Philadelphia: Saunders; 2012. pp. 1503-29.

18. Davis SN, Tate D. Effects of morning hypoglycemia on neuroendocrine and metabolic responses on subsequent afternoon hypoglycemia in normal man. J. Clin. Endocrinol. Metab. 2001; 86(5): 2043-2050.

19. Davis SN, Shavers C, Costa F. Differential gender responses to hypoglycemia are due to alterations in CNS drive and not glycemic thresholds. Am. J. Physiol. Endocrinol. Metab. 2000; 279 (5): E1054-E1063.

20. Davis SN, Shavers C, Mosqueda-Garcia R, Costa F. Effects of differing antecedent hypoglycemia on subsequente counterregulation in normal humans. Diabetes. 1997; 46(8): 1328-35.

21. Drazin MB. Managing the adolescent athlete with type 1 diabetes mellitus. Pediatr. Clin. North Am. 2010; 57:829-837.

22. Franz M. (2002). Nutrition, physical activity, and diabetes. In:Ruderman N, Devlin JT,Schneider SH, editors. Handbook of exercise in diabetes. Alexandria (VA): American Diabetes Association, Inc. 2002. p. 321-37.

23. Frid A, Ostman J, Linde B. Hypoglycemia risk during exercise after intramuscular injection of insulin in the thigh in IDDM. Diabetes Care. 1990; 11: 410-434.

24. Galassetti P, Tate D, Neill RA, Morrey S, Davis SN. Effect of gender on counter-regulatory responses to euglycemic exercise in Type 1 diabetes. J. Clin. Endocrinol. Metab. 2002; 87 (11); 5144-5150.

25. Galassetti P, Tate D, Neill RA, Morrey S, Wasserman DH, Davis $\mathrm{SN}$. Effect of sex on counterregulatory responses to exercise after antecedent hypoglycemia in Type 1 diabetes. Am. J. Physiol. Endocrinol. Metab. 2004; 287 (1): E16-E24.

26. Gallen I. The management of insulin treated diabetes and sport. Pract Diab Int. 2005; 22 (8): 307 - 312.

27. Garber CE, Blissmer B, Deschenes MR, Franklin BA, Lamonte MJ, Lee IM, et al. American college of sports medicine position stand. Quantify and quality of exercise for developing and maintaining cardiorespiratory, musculoskeletal, and neuromotor fitness in apparently healthy adults: guidance for prescribing exercise. Med Sci Sports Exerc. 2011; 43: 1334-1359.

28. Gardim CB, Oliveira BAP, Bernardo AFB, Gomes RL, Pacagneli FL, Lorençoni RM, Valderlei LCM. Heart rate variability in children with type 1 diabetes mellitus. Rev Paul Pediatr. 2014; 32 (2): 279-85.

29. Golbidi S, Badran M, Laher I. Antioxidant and antiinflammatory effects of exercise in diabetic patients. J Diabetes Res. 2012; 1-16.

30. Gonder-Frederick L. Hypoglycemia. In: Franz MJ, editor. A core curriculum for diabetes education: diabetes management therapies. Chicago: American Association of Diabetes Educators. 2001. 279-306.

31. Guelfi KJ, Jones TW, Fournier PA. New insights into managing the risk of hypoglycaemia associated with intermit ten thighintensity exercise in individuals with type 1 diabetes mellitus: implications for existing guidelines. Rev Bras Med Esporte. 2007; 37 (11): 937-946.
32. Guelfi KJ, Jones TW, Fournier PA. Intermittent high-intensity exercise does not increase the risk of early postexercise hypoglycemia in individuals with type 1 diabetes. Diabetes Care. 2005; 28(2): 416-417.

33. Harmer AR, Chisholm DJ, McKenna MJ, Morris NR, Thom JM, Bennett G, Flack JR. High-intensity training improves plasma glucose and acid-base regulation during intermittent maximal exercise in type 1 diabetes. Diabetes Care. 2007; 30 (5): 1269- 1271.

34. Harris GD, White R. Diabetes in the competitive athlete. Current Sports Medicine Reports. 2012; 11(6): 309-315.

35. Iscoe KE, Corcoran M, Riddell MC. High rates of nocturnal hypoglycemia in a unique sports camp for athletes with type 1 diabetes: lessons learned from continuous glucose monitoring. Can J Diabetes. 2008; 32 (3): 182-9.

36. Ivy JL, Katz AL, Cutler CL. Muscle glycogen synthesis after exercise: effect of time of carbohydrate ingestion. J Appl Physiol. 1988; 64: 480-485.

37. Jenni S, Oetliker C, Allemann S. Fuel metabolismo during exercise in euglycaemia and hyperglycaemia in patients with Type 1 diabetes mellitus-a prospective single-blinded randomised crossover trial. Diabetologia. 2008; 51(8): 1457-1465.

38. Jessen N, Goodyear LJ. Contraction signaling to glucose transport in skeletal muscle. J. Appl. Physiol. 2005; 99 (1): 330-337.

39. Jeukendrup AE, Achten J. Fatmax: A new concept to optimize fat oxidation during exercise? European Journal of Sport Science. 2001; 1(5): 1-5.

40. Jimenez CC, Corcoran MH. National athletic trainers' association position statement: management of the athlete with type 1 diabetes mellitus. J Athl Training. 2007; 42 (4): 536-545.

41. Kirk SE. Hypoglycemia in athletes with diabetes. Clin.Sports Med. 2009; 28: 455-468.

42. Kivela R, Silvennoinen M, Touvra AM, Lehti TM, Kainulainen $\mathrm{H}$, Vihko V. Effects of experimental type 1 diabetes and exercise training on angiogenic gene expression. and capillarization in skeletal muscle. FASEB J. 2006; 20 (9): 1570-2.

43. Komatsu WR, Gabbay MA, Castro ML, Saraiva GL, Chacra AR, de Barros Neto TL. Aerobic exercise capacity in normal adolescents and those with type 1 diabetes mellitus. Pediatr Diabetes. 2005; 6 (3): 145-9.

44. Lamounier RN, Mendes GLC, Silva AS, Oliveira ES, Silva AH, Ferreira TM, Giannella-Neto D. Monitoração contínua de glicose em 67 atletas com diabetes mellitus tipo 1 durante corrida de $18 \mathrm{~km}$. Brazilian Archives of endocrinology and metabolismo. 2013; 57 (6): S29.

45. Lee AD, Hansen PA, Schluter J, Gulve EA, Gao J, Holloszy JO. Effects of epinephrine on insulin-stimulated glucose uptake and GLUT-4 phosphorylation in muscle. Am J Physiol. 1997; 273 (3): C1082-7.

46. Lima VA, Leite N, Titski ACK, Souza WC, Mascarenhas LPM. Comparison of acute of aerobic and flashing continuous training in effect of diabetes patients with type 1 blood glucose. Revista Pesquisa em Fisioterapia. 2015; 5 (2): 102-107.

47. Macknight JM, Mistry DJ, Pastors JG, Holmes V, Rynders CA. The daily management of athletes with diabetes. Clin. Sports Med. 2009; 28 (3): 479-95.

48. Marliss EB, Simantirakis E, Miles PDG, Purdon C, Gougeon R, Field C, Halter JB, Vranic M. Glucoregulatory and hormonal 
responses to repeated bouts of intense exercise in normal male subjects. J Appl Physio. 1991; 71: 924-933.

49. Maughan RJ. Impact of mild dehydration on wellness and on exercise performance. Eur J Clin Nutr. 2003; 57 (Suppl 2): S19-S23.

50. Mol P, Vries ST, Koning EJP, Gans ROB, Tack CJ, Bilo HJG. Increased insulin requirements during exercise at very high altitude in type 1 diabetes. Diabetes Care. 2011; 34: 591-595.

51. Nathan D, Madnek S, Delahanty L. Programming preexercise snacks to prevent post-exercise hypoglycemia in intensively treated insulin-dependent diabetics. Ann Intern Med. 1985; 4: 483-6.

52. Nery M. Hypoglycemia as a limiting factor in the management of type 1 diabetes. Brazilian Arquives of Endrocrinol and Metab. 2008; 52(2): 288-298.

53. Nugent AM, Steele IC, Al-Modaris F, Vallely S, Moore A, Campbell NP. Exercise responses in patients with IDDM. Diabetes Care. 1997; 20 (12): 1814-1821.

54. Pierce NS. Diabetes and exercise. Br J Sports Med. 1999; 33: 161-173.

55. Pollock ML, Feigenbaum MS, Brechue WF. Exercise prescription for physical fitness. Quest. 1995; 47: 302-337.

56. Purdon C, Brousson M, Nyveen SL, Miles PDG, Halter JB, Vranic M, Marliss EB. The roles of insulin and catecholamines in the glucoregulatory response during intense exercise and early recovery in insulin-dependent diabetic and control subjects. J Clin Endocrinol Metab. 1993; 76: 566-573.

57. Rabasa-Lhoret R. et al. Guidelines for premeal insulin dose reduction for postprandial exercise of different intensities and durations in type 1 diabetic subjects treated intensively with a basal-bolus insulin regimen (Ultralente-Lispro). Diabetes Care. 2001; 24 (4): 625-630.

58. Ramalho AC, Soares S. The role of exercise in the treatment of type 1 diabetes. Brazilian Arquives of Endrocrinol and Metab. 2008; 52 (2): 260-267.

59. Riddell MC, Iscoe K. Physical activity, sport, and pediatric diabetes. Pediatr Diabetes. 2006; 7: 60-70.

60. Riddell MC, Perkins BA. Exercise and glucose metabolism in persons with diabetes mellitus: perspectives on the role for continuous glucose monitoring. J Diabetes Sci Technol. 2009; 3 (4): $914-923$.

61. Riddell MC, Bar-Or O, Hollidge-Horvat M, Schwarcz HP, Heigenhauser GJ. Glucose ingestion and substrate utilization during exercise in boys with IDDM. J Appl Physio. 2000; 88 (4):1239-46.

62. Rissanen AE, Tikkanen HO, Koponen AS, Aho JM, Peltonen JE. Central and peripheral cardiovascular impairments limit VO2peak in type 1 diabetes. Med Sci Sports Exerc. 2015; 47(2): 223-230.

63. Robertson K, Riddell MC, Guinhouya BC, Adolfsson P, Hanas $\mathrm{R}$. Exercise in children and adolescents with diabetes. Pediatric Diabetes. 2014; 15 (20): 203-223.

64. Robitaille M, Dubé MC, Weisnagel SJ, Prud'homme D, Massicotte D, Péronnet F, Lavoie C. Substrate source utilization during moderate intensity exercise with glucose ingestion in type 1 diabetic patients. J Appl Physiol. 2007; 103 (1): 119-24.

65. Sandoval DA, Aftab-Guy DL, Richardson MA, Ertl AC, Davis SN. Effects of low and moderate antecedente exercise on counterregulatory responses to subsequent hypoglycemia in Type 1 diabetes. Diabetes. 2004; 53(7):1798-1806.
66. Sherman WM, Costill DL, Fink WJ. The effect of exercise and diet manipulation on muscle glycogen and its subsequente use during performance. Int Journal Sports Med. 1981; 2: 114-8.

67. Shilo S, Sotsky M, Shamoon H. Islet hormonal regulation of glucose turnover during exercise in Type 1 diabetes. J. Clin. Endocrinol. Metab. 1990; 70 (1): 162-172.

68. Sigal RJ, Purdon C, Fisher SJ, Halter JB, Vranic M, Marliss EB. Hyperinsulinemia prevents prolonged hyperglycemia after intense exercise in insulin-dependent diabetic subjects. J Clin Endocrinol Metab. 1994; 79(4): 1049-1057.

69. Taplin CE, Cobry E, Messer L, McFann K, Chase HP, FialloScharer R. Preventing post-exercise nocturnal hypoglycemia in children with type 1 diabetes. J Pediatr. 2010; 157(5): 784-788.

70. Thompson WR. editor. ACSM's guidelines for exercise testing and rescription. 8th Edition. PA, USA: Wolters Kluwer Health/ Lippincott Williams \& Wilkins; 2010. Preparticipation health screening and risk stratification; p. 18-39.

71. Thurm U, Harper PN. I'm running on insulin:summary of the history of the International Diabetic Athletes Association. Diabetes Care. 1992; 15: 1811-1823.

72. Tonoli C, Heyman E, Roelands B, Buyse L, Cheng SS, Berthoin S, Meeusen R. Effects of different types of acute and chronic (training) exercise on glycaemic control in type 1 diabetes mellitus: a meta-analysis. Sports Med. 2012; 42 (12): 1059-1080.

73. Tsalikian E, Mauras N, Beck RW, Tamborlane WV, Janz KF, Chase HP. Impact of exercise on overnight glycemic control in children with type 1 diabetes mellitus. J Pediatr. 2005; 147(4): 528-34.

74. Veves A, Saouaf R, Donaghue VM, Mullooly CA, Kistler JA, Giurini JM. Aerobic exercise capacity remains normal despite impaired endothelial function in the micro - and macrocirculation of physically active IDDM patients. Diabetes. 1997; 46 (11): 1846-52.

75. Wasserman DH. Four grams of glucose. Am J Physiol Endocrinol Metab. 2009; 296: E11-E21.

76. Wasserman DH, Spalding JA, Lacy DB, Colburn CA, Goldstein $\mathrm{RE}$, Cherrington AD. Glucagon is a primary controller of hepatic glycogenolysis and gluconeogenesis during muscular work. Am. J. Physiol. Endocrinol. Metab. 1989; 257(1): E108-E117.

77. Wright D, Sherman W, Dernbach A. Carbohydrate feedings before, during, or incombination improve cycling endurance performance. Journal Appl Physiol. 1991; 71: 1082-8.

78. Yardley JE, Sigal RJ, Perkins BA, Riddell M. Performing resistance exercise before aerobic exercise reduces the risk of hypoglycemia in type 1 diabetes: a study using continuous glucose monitoring. Can J Diabetes. 2010; 34 (3): 247-254.

79. Yardle JE, Kenny GP Perkins BA, Riddell MC, Balaa N. et al. Resistance versus aerobic exercise. Diabetes Care. 2013; 36: 537-542.

80. Younk LM, Mikeladze M, Tate D, Davis SN. Exercise-related hypoglycemia in diabetes mellitus. Expert Ver Endocrinol Metab. 2011; 6 (1): 93-108.

81. Zander E, Schulz B, Chlup R, Woltansky P, Lubs D. Muscular exercise in Type 1-diabetics. II. Hormonal and metabolic responses to moderate exercise. Exp. Clin. Endocrinol. 1985; 85 (1); 95-104. 


\section{Acknowledgments}

We would like to thank the following institutions for the financial support received: Coordenação de Aperfeiçoamento de Pessoal de Nível Superior (CAPES), Conselho Nacional de Desenvolvimento Científico e Tecnológico (CNPq), and Fundação Araucária de Apoio ao Desenvolvimento Científico e Tecnológico do Paraná.

\section{Corresponding author}

Luis Paulo Mascarenhas

Email: masca58@hotmail.com

Manuscript received on May 03, 2016

Manuscript accepted on July 05, 2016

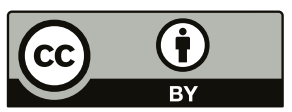

Motriz. The Journal of Physical Education. UNESP. Rio Claro, SP, Brazil - eISSN: 1980-6574 - under a license Creative Commons - Version 3.0 